\title{
Presupuestos extraordinarios
}

Es un motivo de constante preocupación para quien redacta estas líneas, comprobar en el curso del trabajo diario, la desorientación en que se mueven, especialmente, los: péqueños Ayuntamientos, en el enfoque y tramitación de los presupuestos extraordinarios cuyos ingresos están constituídos, en todo o en parte, por operaciones financieras en negociación con el Banco de Crédito Local. de España.

La falta de una legislación que se ocupe con detalle de los documentos que deben formar el expediente de presupuesto extraordinario y la dispersión actual de disposiciones que afectan al problema, son los motivos que provocan, en parte, esta situación. Si estas líneas cumplen el cometido que las lleva a ser publicadas y evitan con ello la búsqueda de legislación aplicable, marcándoles el camino que deben seguir para no perder inútilmente el tiempo o llegar a la formación de expedientes o adopción de acuerdos innecesarios, habré coǹseguido mi objetivo, y con ello, dado satisfacción a los compañeros de los Cuerpos de Secretarios e Interventores, algunos de los cuales, en múltiples ocasiones, y a veces con insistencia, me han requerido para la publicación de un trabajo de esta índole.

La presentación del anteproyecto de presupuesto a la Corporación municipal, formado por el Alcalde Presidente, con el asesoramiento del Secretario y del Interventor de la Corporación, debe ser el punto de arranque para marcar la pauta o camino a seguir y la índole de los acuerdos a adoptar.

$\mathrm{El}$ anteproyecto de presupuesto, bosqueja las partidas de gastos e ingresos que deben formar el presupuesto definitivo; y con el examen de sus recursos, se pone de manifiesto si hay 
- no necesidad de acudir a operaciones financieras y si existe o no enajenación de bienes o valores o pignoración de unos a de otros, como consecuencia de la afección de esta clase de recursos en garantía de las obligaciones derivadas de la formalización del contrato de préstamo o de crédito con el Banco de Crédito Local de España.

El gráfico que insertamos a continuación, tiene como núcleo inicial el anteproyecto de presupuesto, cuyo acuerdo de aprobación por la Corporación municipal puede dar lugar a la formación de cuatro expedientes distintos: uno, orientado hacia e! Banco de Crédito Local de España, que se iniciará con la petición del préstamos necesario para dotar, total o parcialmente. el presupuesto extraordinario; otro expediente, el de referéndum, que se dirigirá al Ministerio de la Gobernación; un tercei expediente, ell de enajenación o gravamen de bienes o de valores, que requerirá la autorización del Ministerio de Hacienda; y un cuarto expediente, el de presupuesto extraordinario, que habrá comenzado ya con la redacción del anteproyecto y que continuará sus trámites normales.

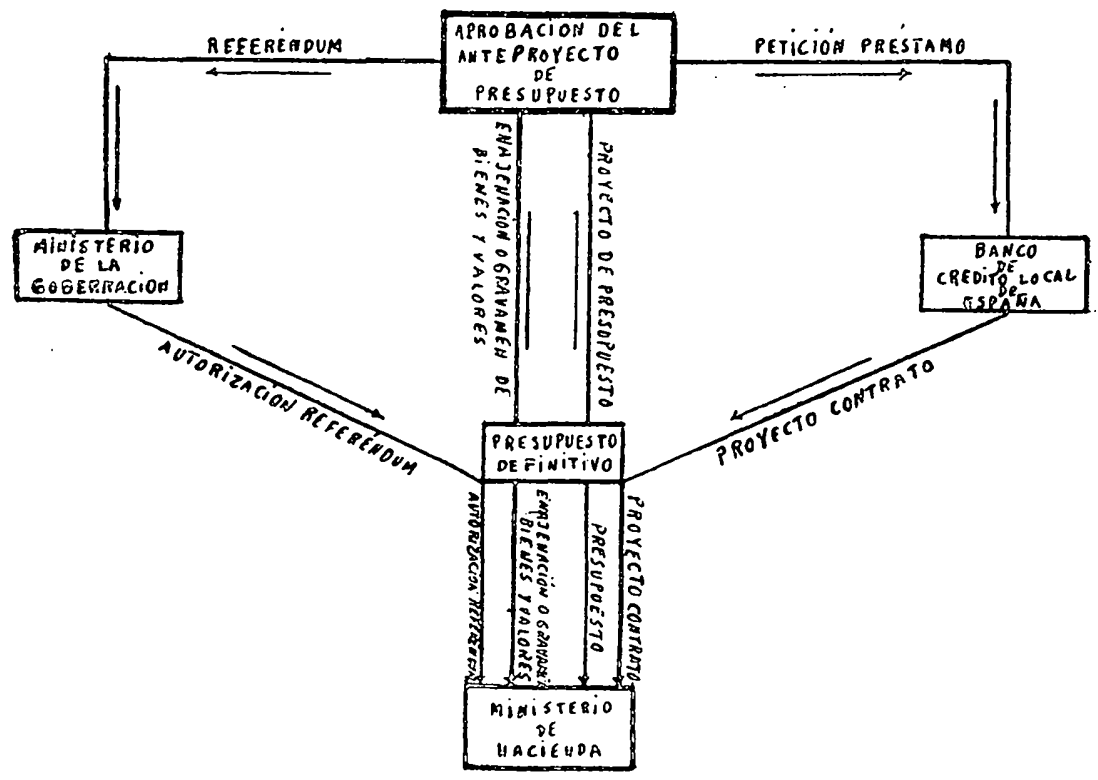


El Banco de Crédito Local, previo estudio de la operación y de sus características, remitirá al Ayuntamiento el proyecto de contrato, que deberá ajustarse a los modelos que inserta la Or. den del Ministerio de Hacienda de $1 .^{\circ}$ de agosto de 1945 ; al Ministerio de la Gobernación, sancionará el expediente de referéndum, en los casos en que sea necesario este trámite y remitirá al Ayuntamiento la autorización correspondiente.

El expediente de presupuesto extraordinario, continuado después de la aprobación del anteproyecto, seguirá sus trámites normales, debiendo coincidir el acuerdo definitivo de su aprobación por el Ayuntamiento con la recepción del proyecto de contrato enviado por el Banco de Crédito Local de España y de la autorización de referéndum, aprobado por el Ministerio de la Gobernación. De este modo, una vez aprobado el presupuesto extraordinario, podrá enviarse el expediente al Ministerio de Hacienda en unión de los documentos remitidos por e: Banco de Crédito Local de España y Ministerio de la Gobernación, a los efectos de que el mencionado Ministerio acuerde:

1. Autorizar la operación de crédito con las características del proyecto de contrato.

2. Aprobar el presupuesto extraordinario y las cantidades que dotan cada finalidad, y

3. Autorizar la enajenación o gravamen de los bienes y. valores municipales, en su caso.

Como resumen de lo expuesto, será conveniente indicar que, en la sesión municipal en la que se dé cuenta del anteproyecto de presupuesto, además del acuerdo inicial de aprobación del mismo y cumplimiento de los trámites legales, podrán adoptarse los siguientes acuerdos que, constituirán, por decirlo así. la cabeza de los respectivos expedientes: de petición de préstamo al Banco de Crédito Local de España por la cantidad que haya sido necesaria para nivelar el presupuesto y dejar dotados los gatos del mismo; de sustitución de los trámites del referéndum ; y de enajenación o gravamen de bienes y valores.

A continuación vamos a ocuparnos de los requisitos y documentos: que deben integrar cada uno de estos expedientes, dejando aparte, a propósito, para que sea objeto de un segundo 
artículo, el concepto referente a las operaciones de crédito con el Banco de Crédito Local de España, por exigirlo así la importancia que dicha Institución tiene hoy para las Corporaciones locales y la extensión de la materia que ha de ser tratada.

Referéndum: trámites sustitutivos del mismo.-El Decreto de 25 de enero de 1946 sobre Ordenación Provisional de las Haciendas locales, no exige el referéndum para los acuerdos municipales relativos a empréstitos, cualquiera que sea el porcentaje de aumento que el servicio de intereses y amortización represente en el presupuesto ordinario de gastos.

Así, pues, ha quedado suprimido el artículo 545 del Estatuto -Municipal que exigía que los acuerdos municipales relativos a empréstitos, fueran sometidos a la aprobación por referéndum cuando exigiesen para su servicio de amortización e interese; un aumento superior al 3 por 100 del presupuesto ordinario de gastos, y la Ley de 18 de junio de 1936, que establ-cía que en los Ayuntamientos que fueran capitales de provincia o tuvieser: una población mayor de $\mathbf{5 0 . 0 0 0}$ habitantes, no se exigiría el referéndum más que en el caso de que el servicio de intereses $y$ amortización produjese un aumento de más del 10 por 100 en el presupuesto municipal de gastos.

La Ley municipal de 31 de octubre de 1935, exige el referéndum para la enajenación de bienes o valores del patrimonio municipal cuyo importe exceda del 20 por 100 del presupuesto ordinario de ingresos. Por tanto, si han de enajenarse o gravarse en garantía de operaciones de crédito, bienes o valores patrimoniales cuyo importe exceda de este porcentaje, con objeto de nutrir con su producto los gastos de un presupuesto extraordinario, o dejarlos en garantía de operaciones de crédito, la Corporación municipal vendrá obligada a instruir el expediente de referéndum al objeto de que el acuerdo de enajenación o gravamen sea ejecutivo.

La intervención vecinal en los acuerdos municipales por medio del referéndum, a que se refieren los artículos 89 al 97 de la Ley municipal de 31 de octubre de 1935 , ha sido sustituida por las formalidades y requisitos establecidos por el Decreto de 25 de marzo de 1938. 
Según esta disposición, el acuerdo de enajenación de los bienes o valores patrimoniales, o de su gravamen, se adoptará por mayoría de dos terceras partes de concurrentes, en primera convocatoria, siempre que a la sesión asista cuando menos las cuatro quintas partes de los elementos que integran de derecho la Corporación y, por igual mayoría, en segunda convocatoria, pero bastando en este caso que concurra la mitad más uno de los elementos integrantes. Entre una y otra sesión, habrá de transcurrir un plazo mínimo de ocho días naturales.

Adoptado el acuerdo, se dispondrá la inmediata publicación de un extracto del mismo en el "Boletín Oficial" de la provincia y la apertura de una información pública, a la que sólo podrán acudir por escrito, y ante el Gobernador civil o el Ayuntamiento interesado, las personas naturales y jurídicas a zuyo particular interés afecte directa y especialmete el acuerdo de que se trate y las Corporaciones o entidades de interés público o general y de carácter social o económico radicantes en el respectivo término municipal.

Transcurrido el plazo de quince días naturales, a partir de la publicación, el Ayuntamiento remitirá el expediente al Gobernador civil de la provincia, quien, en el término de ocho días, lo elevará al Ministerio de la Gobernación junto con las reclamaciones que se hubieran presentado, y con el informe de aquella autoridad provincial. El Ministerio de la Gobernación, previos los dictámenes que estime oportunos, resolverá en definitiva, en el plazo de un mes, desde que el expediente tuviese entrada en el Registro general del Departamento.

Enajenación o gravamen de bienes y vailores.- $-\mathrm{El}$ acuerdo de enajenación o gravamen de bienes y valores patrimoniales, es de la competencia del Ayuntamiento Pleno y, en su caso, de la Comisión Permanente, cuando su precio total no sea superior a $\mathbf{2 5 . 0 0 0}$ pesetas en los Municipios mayores de $\mathbf{1 0 0 . 0 0 0}$ residentes y no superior a $\mathbf{1 5 . 0 0 0}$ pesetas en los demás.

Sin embargo, si la enajenación o gravamen se efectúa como consecuencia de presupuestos extraordinarios o como garantía de operaciones de crédito que nivelen dichos presupuestos el acuerdo será lógico que sea adoptado por el Pleno del Ayun- 
tamiento en la misma sesión en que se apruebe el anteproyecto de presupuesto extraordinario.

El hecho de necesitar la sanción ministerial para que el acuerdo sea ejecutivo, implica la necesidad de que sea expuesto al público para reclamaciones por término de quince días. La exposición del acuerdo se efectuará mediante anuncio en el rBoletín Oficial" de la provincia.

El acuerdo inicial y la exposición posterior con las reclamaciones que en su caso se hubiesen presentado, se elevará junto con los expedientes de presupuesto extraordinario, proyecto de contrato y referéndum al Ministerio de Hacienda, por medio del Delegado correspondiente y con su informe previo, a tenor de lo establecido en el artículo 332 del Decreto de 25 de enero de 1946.

Habrá de tenerse en cuenta que el expediente de referéndum es por completo independiente del de enajenación o gravamen de bienes y valores $\mathrm{y}$, por tanto, sus acuerdos y sus trámites, deben efectuarse por separado.

Presupuesto extraordinario.-La formación del anteproyecto de presupuesto extraordinario corresponde al Presidente de la Corporación que, a tales efectos, estará asistido por el Secretario y el Interventor.

Este anteproyecto será redactado en cuanto a gastos, con arreglo al modelo que oficialmente se apruebe, dividiéndolo en capítulos, artículos, conceptos y partidas, numeradas éstas correlativamente en la totalidad del presupuesto; cada concepto contendrá la dotación específica para cada obra o servicio, quedando prohibidas las agrupaciones de éstos y el uso de frases que impidan apreciar la naturaleza o el coste de cada uno.

En relación con los ingresos, el anteproyecto se redactará igualmente por.capítulos, artículos, conceptos y partidas, expre. sando con detalle el importe íntegro de las subvenciones otorgadas, donativos, ingresos eventuales o transitorios, contribuciones especiales, sobrantes de presupuestos ordinarios si los hay, etcétera, y en último término, si la suma de estos ingresos no fuera suficiente para cubrir los gastos, la cantidad que habrá de 
pedirse en préstamos para igualar la cifra total del presupuesto y nivelar los ingresos con los gastos.

El anteproyecto no podrá formarse con déficit, permitiéndose, sin embargo, que se le forme con nivelación de gastos e ingresos o con exceso de éstos sobre aquéllos, es decir, con superávit, salvo cuando los gastos estén dotados, en todo o en parte, con el producto de operaciones de crédito, en que se presentará siempre nivelado.

Los conceptos de gastos y de ingresos se agruparán por artículos, quedando comprendidos de tal modo la totalidad de los conceptos en tantas relaciones como artículos existan. Los artículos o relaciones que correspondan a un mismo Capítulo, se comprenderán en Carpetas que llevarán relacionado el número de cada artículo, el título del mismo y la cifra de gasto e ingreso, de manera que, sumadas las cifras de estos artículos, resulte el gasto o ingreso total del Capítulo correspondiente.

Los resúmenes del presupuesto por artículos y capítulos se harán tomando como base las cifras que arrojen cada una de las Relaciones y Carpetas formadas.

$\mathrm{Al}$ anteproyecto se unirán: la Memoria económica redactada por el Presidente de la Corporación con el asesoramiento de los funcionarios técnicos antes dichosi; certificación explicativa del sobrante obtenido en el último ejercicio liquidado y los motivos de la reserva o de su aplicación parcial cuando no se destinase al presupuesto la totalidad de dicho sobrante; otra del acuerdo de imposición de contribuciones especiales o, en su caso, de la imposibilidad de imponerlas por tratarse de obras o servicios que no dan lugar a ellas; otra del facultativo en la que con referencia a los proyectos técnicos aprobados por la Corporación se haga constar el importe de las obras o servicios a realizar y el plan financiero para su ejecución; otras certificaciones que acrediten la exactitud de cualquier otro gasto consignado; articulado o bases complementarias del presupuesto; el informe del Interventor y el dictamen que emita la Comisión de Hacienda. En su caso, también se acompañará copia 
certificada de las subvenciones, donativos o ingresos especiales obtenidos.

El anteproyecto así formado se pasará a la aprobación inicial de la Corporación, exponiéndolo a continuación al público durante quince días mediante anuncio en el "Boletín Oficial" de la provincia.

Podrán reclamar contra el anteproyecto, convertido ya en proyecto, los habitantes en el término municipal, las personas interesadas directamente aunque no habiten en el territorio de la entidad local, y las Corporaciones, Asociaciones y personas jurídicas en general, radiquen o no en el territorio de la entidad, cuando el presupuesto afecte a sus intereses sociales o a los individuales de alguno de sus asociados, siempre que, en este último caso, tuviesen la facultad de gestionarlos o defenderlos con arreglo a las normas legales o a las disposiciones de sus Estatutos.

Las reclamaciones podrán entablarse por no haberse ajustado su elaboración y aprobación a los trámites establecidos por el Decreto de 25 de enero de 1946 , por la inclusión de dotaciones cuya finalidad no sean gastos de primer establecimiento $y$ por ser de manifiesta insuficiencia los ingresos con relación a los gastos o haberse omitido la inclusión de algún ingreso que fuera procedente antes de acudir a la operación de crédito.

Terminado el plazo de exposición al público, la Corporación, en sesión extraordinaria, estudiará y resolverá las observaciones y reclamaciones presentadas y aprobará o no el proyecto, convirtiéndolo en presupuesto definitivo, requiriéndose para aprobarlo el voto favorable de los dos tercios del número de sus miembros de hecho, y, en todo caso, de la mayoría absoluta del número legal.

Aprobado el presupuesto por la Corporación, se expondrá al público con sus anexos por quince días, durante los cuales podrán las personas interesadas a que se ha hecho referencia y por las mismas causas apuntadas, presentar reclamaciones a la Corporación para que ésta las curse debidamente informadas al Ministro o Delegado de Hacienda, según los casos.

La Corporación remitirá al Delegado de Hacienda copia auto- 
rizada del expediente tramitado, dei presupuesto y sus anexos, de las reclamaciones si las hubiere y de los informes emitidos. Cuando se trate de presupuestos extraordinarios que no requieran operación de crédito y haya o no reclamaciones, ia resolución de éstas y la aprobación de aquéllos, corresponde al Delegado de Hacienda.

El Delegado de Hacienda deberá resolver en el plazo de un mes, a partir de la recepción de los documentos. Este plazo se entenderá ampliado en tanto días como emplee la Corporación en enviar los informes, datos y documentos, si el Delegado los solicitara como requisito previo a su decisión.

Contra las resoluciones del Delegado en materia de presupuestos extraordinarios, sólo se admitirá el recurso de alzada ante el Ministro de Hacienda, sin recurso ulterior.

Cuando los presupuestos extraordinarios requieran operación de crédito, el Delegado de Hacienda enviará toda la documentación recibida, con su informe, en el plazo de quince días, al Ministro de Hacienda, que resolverá dentro de los noventa días siguientes a la recepción de los documentos, siendo ampliado este plazo en tantos días como la Corporación emplee en enviar al Ministerio los informes, datos y documentos si el Ministro los solicitara como requisito previo a su decisión. Contra la resolucón del Ministro no se dará recurso alguno.

Los documentos que, por regla general, deberán enviar las Corporaciones al Delegado de Hacienda para su elevación inmediata al Ministerio, serán los siguientes:

a) Copia autorizada del presupuesto extraordinario y del expediente tramitado con los documentos anexos.

b) Las reclamaciones presentadas después del acuerdo definitivo de aprobación del presupuesto y el informe que para cada una de ellas haya sido emitido por la Corporación.

c) Copia literal certificada del proyecto de contrato con el Banco de Crédito Local de España, con especificación del acuerdo adoptado por el Ayuntamiento.

d) Bases de conversión o de sustitución de deuda municipal si el presupuesto extraordinario persiguiera esta finalidad.

e) Expediente de municipalización de servicios públicos, en 
el que, aparte de su tramitación, se hará constar la valoración dada al servicio y las normas empleadas para determinar su coste.

f) Copia certificada de la Orden del Ministerio de la Gobernación aprobatoria del trámite sustitutivo del referéndum, conforme al Decreto de 25 de marzo de 1938, y

g) Copia certificada del expediente de enajenación o gravamen de bienes patrimoniales.

\section{Juan Grau Marín.}

Interventor de Fondos de Administración Local y Jefe de la Sección Técnica de Administración

(Continuará.) 